\title{
A entrada para reserva no serviço militar, a ruptura de um vínculo forte e intenso
}

Joining the reserve in the military service, a break of strong and intense tie

\section{Ana Paula Grillo Rodrigues}

Escola Superior de Administração e Gerência (UDESC)

email:agrillorodrigues@gmail.com

\section{Rafael Dagostin Viscardi}

Msc, Escola Superior de Administração e Gerência (UDESC)

email: rafaeldagostin@gmail.com

\section{Diego Fernandes Ungari}

Msc, Escola Superior de Administração e Gerência (UDESC)

email: diegoungari04@gmail.com

\section{RESUMO}

Este artigo busca compreender as mudanças do vínculo e as estratégias de regulação emocional, a partir da percepção do Oficial da Polícia Militar, no processo para a reserva. A pesquisa tem uma abordagem qualitativa, feita a partir de entrevista semiestruturada. O método de análise escolhido foi a análise de conteúdo, na qual foi definida uma categorização das narrativas dos oficiais, dividida em dois construtos: O Vínculo Organizacional e a Regulação Emocional. A teoria base vem dos trabalhos de Silva e Bastos (2010), Rodrigues e Bastos (2011) e Gross (1999). Foram encontrados todos os padrões de vínculos e as estratégias de regulação emocional apontados pelas teorias referenciadas. A mudança do vínculo no processo para a reserva é um evento não delimitado no tempo, quanto mais forte o vínculo de comprometimento maior a intensidade da mudança. O pensar a reserva dá início ao processo, e a sintonia em que o oficial se encontra com a organização dita sua intensidade.

Palavras-Chave: reserva; Polícia Militar; vínculos organizacionais; regulação emocional.

\section{ABSTRACT}

This article tries to understand the change of the tie and the emotional regulation, in the perception of the officer of the Military Police, in the process for joining the reserve. It has a qualitative approach, and as a method of collection, semi-structured interviews were chosen. The analysis method chosen was content analysis. A categorization of official narratives was defined, divided into two constructs: The Organizational Tie and Emotional Regulation. The basic theory comes from the works of Silva and Bastos (2010), Rodrigues and Bastos (2011) and Gross (1999). All the patterns of ties pointed out by the referenced theory were found. Emotional regulation strategies were present in the same way. The change of the tie in the process to the reserve is an event not delimited in time, the greater the tie of commitment the greater the intensity of the change. The thought of reserving the start of the process, and the attunement in which the official meets the organization dictates its intensity.

Key-words: reservation; Military Police; organizational ties; emotional regulation 


\section{INTRODUÇÃO}

O trabalho ocupa grande parte da vida do ser humano e pode ser considerado como um norteador na organização de sua vida social e um forte constituinte da dimensão psicológica (ZANELLI; SILVA, 1996). Além disso o trabalho se apresenta como um forte componente na configuração de identidade do indivíduo, impactando diretamente na forma como se mostra ao mundo e em suas interações sociais. Ao permear sua história de vida singular e coletiva, o trabalho promove sentidos para a existência do ser humano (SANTOS, 1990). Os vínculos estabelecidos no contexto laboral, seja com o trabalho, com a organização, profissão ou até mesmo com o grupo de pessoas no qual o indivíduo está inserido, são fortes e podem ocupar a centralidade na vida para grande parte das pessoas.

A força dos vínculos varia de acordo com as percepções que os indivíduos têm da organização e do trabalho. Algumas organizações, seja pela natureza das atividades, seja pela cultura ou pela sua estrutura, apresentam fortes laços, isso porque, em qualquer área de atuação, além das questões que envolvem o papel do trabalho na construção identitária do sujeito, é necessário o investimento de tempo e esforços durante anos para que desempenhe o papel a ele atribuído.

Dentre as organizações que podem apresentar um alto rigor sobre a atividade laboral, a Polícia Militar (PM), escolhida como foco deste trabalho, destaca-se pela própria natureza da atividade, uma vez que a estrutura do militarismo é forjada sob a máxima da hierarquia e disciplina como instrumentos necessários para o bom funcionamento do sistema institucional. Os policiais militares devem exercer suas funções de forma ininterrupta, respeitando e seguindo os preceitos institucionais mesmo nos momentos de folga. A dedicação e a fidelidade perpassam aqui o espaço de trabalho, migrando para suas vidas pessoais de forma bastante intensa. Nessa perspectiva, dado o regime de extrema dedicação requerido pelo trabalho, os policiais militares, muitas vezes, distanciam-se de outros grupos sociais, e não raramente, da própria família.

Assim, quando se dá a aproximação do rompimento com o vínculo institucional, que na Polícia
Militar é chamado de reserva remunerada, é compreensível que o indivíduo sofra com a sensação de inutilidade, principalmente, se esse afastamento ocorrer de forma abrupta e sem preparação (TSUTSUI, 2009). A passagem para a reserva se dá legalmente após 30 anos de serviços prestados à corporação no caso dos policiais de sexo masculino e 25 anos no caso das policiais femininas, ou seja, ocorre nesse momento o rompimento abrupto da ligação com a organização após anos investidos em uma atividade na qual se exige fortes vínculos, quando se trata de Praças, num âmbito mais operacional e quando se trata de Oficiais, num âmbito mais voltado à gestão organizacional.

Kegler et al. (2015) retratam esse cenário ao constatar um alto índice de complicações sociais de militares que passaram para a reserva, inclusive com aumento de ocorrência de queixas médicas e/ou psicológicas (KEGLER et al., 2015).

De acordo com Silva (2009), para que se possa desfrutar positivamente da aposentadoria, é necessário que se prepare para ela. No entanto, é grande o número de trabalhadores que não consideram o fato de que, ao se aposentarem, não saberão como gerenciar a situação, seja por não saberem como utilizar o tempo livre, por uma possível queda na renda familiar ou ainda pelas mudanças na relação com a família ou perda de status (LOPES, 2010).

A entrada para reserva e a ruptura com a rotina do trabalho militar, é um momento que requer reorganização da vida familiar, reconfiguração das relações afetivas, novos espaços de convívio, relacionamentos fora do mundo do trabalho e novos hábitos cotidianos. O tempo livre do militar na reserva pode ser vivenciado de modo ambivalente: pode ser usado para o desenvolvimento pessoal na busca de novos caminhos, mas também experimentado como um tempo sem sentido, em que no passado esse sentido era preenchido pelo trabalho. Assim, é importante o desenvolvimento de um ócio com sentido nesta fase da vida; entretanto, poucas pessoas desenvolvem práticas que possibilitem o uso do tempo livre de forma que as satisfaçam (CABEZA, 2009).

Nesse processo de ruptura de vínculo e assimilação de uma nova rotina, o bom uso das emoções é essencial para a manutenção do equilíbrio psíquico. $\mathrm{O}$ uso da inteligência emocional se torna um divisor 
de águas para a vida, que agora precisa ser ressignificada. A administração adequada das emoções, na forma como o indivíduo vai encarar a volta para casa, a ausência de uma atividade institucional, a mudança do status profissional, deveria ser prioritária. Dentro da inteligência emocional, as estratégias de regulação emocional irão definir a forma como o indivíduo vai se apresentar emocionalmente ao contexto. De acordo com Gross (1998), regulação emocional é definida como processos conscientes, inconscientes, automáticos e controlados de mudança da expressão emocional e dos estados internos para modificar a experiência pessoal, a fim de uma melhor adaptação ao cenário no qual o indivíduo se encontra. As estratégias de regulação emocional tornam-se essenciais para a adaptação do indivíduo a novas circunstâncias da vida, como no caso do escopo desse artigo, na ruptura do vínculo institucional e entrada para a reserva.

Diante do senso comum sobre a entrada do militar para reserva, alguns pressupostos foram levantados. Por ser, a profissão militar, uma profissão antiga e bastante explorada por diversas mídias, os indivíduos que se dispõem a ingressar numa corporação, conhecem a natureza do trabalho e, mesmo que superficialmente, conhecem a cultura militar. Por esse motivo, os valores do indivíduo são compatíveis com o da corporação, alimentando o pressuposto de que o vínculo de Comprometimento é forte pela identificação à natureza do trabalho e pela cultura militar. Outro pressuposto é de que o militar, por participar de uma rotina com inúmeras atividades, pensará na ruptura do vínculo com a corporação somente próximo da data da entrada para a reserva, não apresentando estratégias de regulação emocional frente ao que lhe espera, gerando mais sofrimento com a sua saída da instituição. Relacionado a esse pressuposto pode-se considerar que a reserva é caracterizada por sentimentos de vazio e insegurança psíquica. Seguindo essa linha de raciocínio, pressupõe-se ainda que a instituição não prepara o militar para sua saída, gerando uma ruptura abrupta rodeada de muitos sofrimentos. E por fim, analisando os vínculos, pode-se pensar que o Consentimento aparece fortemente na estrutura da relação do indivíduo com a organização, devido à sua natureza pautada na obediência e na hierarquia. Destaca-se aqui, diante de inúmeros pressupostos refletidos apenas pelo senso comum, uma escassez de literatura de estudos científicos a esse respeito. Essa escassez é ainda maior quando relacionada com os vínculos, como mostra revisão da literatura desenvolvida por Ungari (2019), apontando que nos últimos 10 anos foram encontrados apenas 44 artigos sobre o tema, sendo que destes nenhum de origem pátria, portanto não explorando as peculiaridades das instituições militares no Brasil. Essa escassez é ainda maior quando se trata de um estudo sobre os vínculos na Polícia Militar de Santa Catarina (ALVARES, GRILLO RODRIGUES, 2019; UNGARI, GRIILO RODRIGUES, 2020).

Essa carência de produção aponta para a existência de uma significativa lacuna, bem como demonstra a frutífera possibilidade de estudos concernentes às peculiaridades que envolvem o processo para a reserva no meio militar.

Nesse sentido, o presente artigo busca compreender, pela percepção do oficial da polícia militar, o processo de mudança do vínculo organizacional diante a passagem para reserva e, ainda, analisar de que forma os processos de regulação emocional se manifestam nestes indivíduos para lidarem com essa mudança em seu papel social.

Cabe ressaltar, que apesar da regulação emocional ser um processo mental do indivíduo, a organização pode assumir um papel fundamental amparando-o por meio de práticas e ações institucionais que o auxiliem no desenvolvimento de mecanismos para se adaptar frente aos desafios que irão surgir durante e depois do processo para reserva.

Assim, optou-se por realizar um estudo de caso na Polícia Militar de Santa Catarina (PMSC), pois como mencionado, o trabalho policial exige do indivíduo altos níveis de comprometimento e desempenho. Portanto entende-se que sua passagem para a inatividade laboral possa ser um período emocionalmente difícil. Com isso, o desenvolvimento deste estudo justifica-se como uma importante ferramenta para que a Polícia Militar e eventualmente outras organizações com estruturas semelhantes, compreendam de forma mais clara os reflexos emocionais do processo de rompimento de vínculo e, com isso, possam desenvolver ações institucionais para amenizar ou facilitar os efeitos desse período, zelando pelo bem-estar e pela saúde do indivíduo. 


\section{O VÍNCULO ORGANIZACIONAL}

Para Rodrigues e Bastos (2011) a ideia de vínculo está associada à capacidade de unir, de criar um elo, que poderá ser mantido por algum tipo de relação de troca. Kanan (2008) diz que vínculos são percepções formadas decorrentes das cognições e afetos. São originados das atitudes, emoções e sentimentos, da exploração de fatos e conceitos, dos pensamentos, crenças, expectativas, recordações, raciocínios, entre outros.

O vínculo é uma estrutura na qual estão incluídos um indivíduo, um objeto e uma relação particular entre eles - do indivíduo ante o objeto e vice-versa -, ambos cumprindo determinada função (PICHON-RIVIĖRE, 2000). Portanto, o vínculo faz parte de uma relação particular com o objeto que resulta numa pauta de conduta, que se traduz na forma observável do vínculo, sendo possível identificar nela (na conduta) a sua expressão (vínculo). Assim a forma como um indivíduo irá se comportar na organização, que é o objeto, está diretamente relacionada com o estabelecimento de vínculos entre ambos (KRAMER, 2003).

$O$ processo de vinculação, segundo aponta Grillo Rodrigues (2012), possui dois momentos: o seu estabelecimento, que é o momento da junção, e a sua manutenção. $\mathrm{O}$ estabelecimento do vínculo ocorre a partir do momento em que o indivíduo e a organização percebem que pode existir uma relação de troca com ganhos mútuos. Já a sua manutenção é um processo mais complexo, pois pode tomar diversos rumos.

O vínculo pode ser guiado por um sentimento de orgulho caracterizado por uma ligação ativa, ou muitas vezes, por comportamentos passivos, manifestados por intermédio do medo de enfrentar o mercado, ou pelo medo de possíveis perdas que ocorrerão se esse indivíduo deixar a organização (GRILLO RODRIGUES, 2012). No aspecto ativo do vínculo encontra-se o Comprometimento, enquanto o Consentimento e Entrincheiramento são caracterizados por estarem ligados a aspectos passivos.

No estudo dos vínculos, destacam-se então os três: Comprometimento, Entrincheiramento e Consentimento. Silva em estudos desenvolvidos com Bastos (2010) e Rodrigues e Bastos (2011) destrincharam as dimensões normativa e calculativa da teoria tridimensional de Meyer e Allen (1991), passando então a considerar o Comprometimento como um construto unidimensional, formado apenas pela base afetiva, que por sua vez se evidencia a partir de três características principais: uma forte crença e aceitação de valores e objetivos da organização; um forte desejo de manter o vínculo com a organização; e a intenção de esforço em favor da organização (BASTOS, 1994).

O que para Meyer e Allen (1991) era chamado de comprometimento instrumental ou de continuação, para Rodrigues e Bastos (2011) passou a ser chamado de Entrincheiramento. Para Pinho et al. (2015), o Entrincheiramento Organizacional, possui um caráter estático, deixando o indivíduo em uma posição defensiva na organização, muitas vezes associado à falta de oportunidades e o bloqueio em desenvolver uma carreira mais compatível com o seu perfil. Entrincheiramento, portanto, diz respeito à decisão de continuar na mesma linha de ação profissional por falta de opções, pela sensação de perda dos investimentos já realizados, ou pela percepção de um preço emocional a pagar muito alto para mudar. A essência deste vínculo envolve a noção de o indivíduo estar preso numa organização por não conseguir visualizar uma alternativa que o sustente de acordo com suas necessidades e expectativas. Rodrigues e Bastos (2011) acrescentam que não é possível falar de uma permanência espontânea do trabalhador entrincheirado, mas sim em decorrência da sua necessidade.

Com tudo isso, a literatura adotada entende o Entrincheiramento refere-se a um vínculo composto por três geradores: Ajustamentos a Posição Social, que diz respeito ao sentimento de que a saída da organização representaria perda do que foi investido para se manter ali. Os Arranjos Burocráticos Impessoais dizem respeito a preocupação com as eventuais perdas financeiras que podem ocorrer com a saída da organização. Por fim, a Limitação de Alternativas trate-se da falta de perspectiva do sujeito em relação a outras oportunidades de trabalho (RODRIGUES, BASTOS, 2012).

$\mathrm{O}$ vínculo do individuo com sua organização, quando mais fortemente caracterizado por um sentimento de lealdade, de obediência, de adesão às normas e procedimentos organizacionais, aspectos estes que são condizentes com o dia-a-dia do oficial da polícia militar, pode constituir-se menos em Comprometimento e mais em obediência ou 
Consentimento Organizacional, como proposto por Silva e Bastos (2010).

O conceito de Consentimento Organizacional apresentado aqui se baseia na definição destes autores, que considera este vínculo como bidimensional, composto pelos geradores Obediência Cega e Aceitação Întima.

O gerador Obediência Cega significa cumprimento automático da ordem, sem envolver avaliação ou julgamento a respeito desta. O trabalhador se comporta de acordo com as ordens estabelecidas pelo seu superior hierárquico e não se considera responsável por nenhuma consequência, principalmente negativa, que possa advir de suas ações. Já a Aceitação Întima significa cumprimento das normas e regras estabelecidas em função de uma concordância autêntica com as mesmas. Há, portanto, similaridade entre as visões do indivíduo e da organização, o que o levaria a uma identificação com as regras, os procedimentos e os valores que embasam as decisões dos superiores (SILVA; BASTOS, 2010).

Cabe ainda ressaltar que os três vínculos aqui abordados não são excludentes, podendo coexistir simultaneamente e formar combinações entre eles.

\section{REGULAÇÃO EMOCIONAL}

A regulação emocional pode ser definida como uma tentativa controlada ou automática de lidar com as emoções, indicando quando e a maneira como elas serão sentidas e expressas (GROSS, 2013). O processo de regulação emocional consiste, portanto, em manejar emoções para que o indivíduo se adapte melhor ao contexto em que se encontra, sendo capaz de modular a emoção quanto ao tempo de duração, magnitude e latência. Suas funções são defender o indivíduo de situações indesejáveis, evitar sofrimentos ou manter situações agradáveis, com o intuito de preservar o seu bem-estar (GROSS, 2013).

A teoria de James J. Gross (1998,1999), distingue dois grandes grupos de estratégias de regulação emocional, focadas nos aspectos antecedentes e nos consequentes. Estratégias focadas em aspectos antecedentes referem-se à coisas que fazemos antes que as tendências de resposta emocional se tornem totalmente ativadas e mudem nosso comportamento e resposta fisiológica periférica. A estratégia de regulação emocional antecedentes é considerada mais profunda que a consequente e consiste na modificação consciente e voluntária dos sentimentos para expressar emoções associadas as demandas de trabalho (GONDIM et al., 2017). O indivíduo controla a situação e a percepção da situação desencadeadora de emoções por meio da: Seleção da situação (aproximar ou se distanciar de pessoas, objetos e eventos para evitar emoções indesejáveis ou fazer vir à tona emoções desejáveis); Modificação da situação (expressar emoções intencionais para mudar o curso da interação em andamento); Atenção posicionada (redirecionar o foco da atenção para: distração, concentração e a ruminação) e a Mudança cognitiva (negar e interpretar positiva ou negativamente, comparar o que se sente com o que outras pessoas sentem em situações semelhantes ou reavaliar a situação de uma perspectiva distinta para atenuar o seu impacto emocional).

As estratégias focadas nos aspectos consequentes referem-se à coisas que fazemos quando uma emoção já está em andamento, depois que as tendências de resposta foram geradas. Consideradas ações superficiais, nas quais o indivíduo tenta mudar os estados fisiológicos pessoais e a expressão da emoção por meio de: Mudar estados fisiológicos: (exercícios respiratórios, de biofeedback e de relaxamento, uso de tranquilizantes, relaxantes musculares, álcool, comida, cigarro, etc.); Regulação da expressão (feita por meio da supressão - tentar não mostrar - ou da intensificação - fazer questão de mostrar - para modular a experiência emocional); Compartilhamento social das emoções (as pessoas escrevem em diários e também conversam com amigos ou até mesmo desconhecidos sobre os seus sentimentos na tentativa de atenuá-los ou modificá-los).

Regular emoções não costuma ser tarefa fácil. Nas palavras de Gondim e Borges (2020), diante de situações desconfortáveis, estamos mais preparados a reagir por impulso do que tolerar sentimentos que nos incomodam, o que faz que muitas vezes nos esquivemos ou menosprezamos a importância do enfrentamento de situações difíceis (GONDIM, BORGES, 2020). Cabe ressaltar ainda que a habilidade de regular as emoções faz parte de um mecanismo de adaptação do indivíduo ao meio, e as pessoas que não conseguem usar esse recurso de forma hábil 
correm o risco de sofrerem danos mais severos de ordem física e psicológica.

\section{PROCEDIMENTOS METODOLÓGICOS}

A abordagem escolhida para este artigo foi a qualitativa, que se destina para casos em que o objetivo é a "demonstração lógica das relações entre conceitos e fenômenos, com o objetivo de explicar a dinâmica dessas relações em termos intersubjetivos" (MENDES, 2006). Dentre suas características o artigo se enquadra em um estudo de caso que segundo Stake (2011) é uma estratégia adequada para explorar fenômenos complexos e experiências pessoais dentro de um contexto específico. Neste caso, o contexto diz respeito a organizações militares e suas particularidades, como é a reserva remunerada.

A análise e desenvolvimento do objeto deste estudo se dá dentro de um determinado conjunto de suposições sobre a natureza da organização "Polícia Militar", a natureza do trabalho policial, os significados que o oficial tem de si e do seu trabalho, e a relação entre eles. O foco principal do presente estudo não é a quantificação, mas a compreensão e caracterização da dinâmica das relações que envolvem o fenômeno da reserva remunerada.

Como método de coleta foram realizadas entrevistas semiestruturadas em profundidade. Godoi e Balsini (2010) nos dizem que o objetivo de usar a entrevista "em profundidade" como método de coleta de dados é abordar a complexidade organizacional e as relações que a permeiam a partir do ponto de vista subjetivo dos indivíduos envolvidos nesse contexto. A opção pela entrevista semiestruturada ainda se relaciona com ênfase na teoria, ou seja, está associada à teoria a priori, com categorias analíticas definidas, neste caso, os construtos Vínculo Organizacional e Regulação Emocional. Para a melhor condução das entrevistas foi desenvolvido um roteiro com perguntas abertas focadas nos dois temas centrais ou construtos já citados.

A seguir será apresentado o roteiro da entrevista com as perguntas em itálico e as análises teóricas que as orientaram.
1) O que levou você a ingressar na PMSC? Quais foram suas motivações? Pergunta introdutória que visou verificar quais aspectos inicialmente vincularam o militar à corporação.

2) Uma vez fazendo parte da instituição suas expectativas se concretizaram? Em caso negativo o que mudou? Tanto a pergunta 1 quanto a 2 tiveram como foco extrair dos sujeitos informações referentes a valores e expectativas, especialmente relativos ao Comprometimento, baseados em Bastos (1994), e ao que levou o militar decidir fazer parte da corporação no momento de estabelecimento dos vínculos (GRILLO RODRIGUES, 2012).

3) Seus valores pessoais sempre estiveram em sintonia com os valores da instituição? Houve algum momento de conflito em relação a este ponto? Como você lidou com isso? Essa pergunta remete a questões relativas especialmente ao Consentimento (SILVA, 2009), abordando o sujeito sobre a concordância dos valores da corporação.

4) Em algum momento na carreira vocêpensou em se afastar da instituição? Por quê? A intenção de afastamento está relacionada ao Entrincheiramento (RODRIGUES, BASTOS, 2011), quando aborda, apesar de uma possível intenção de se afastar, a decisão de permanecer na corporação pode apontar para um possível vínculo de entrincheiramento.

5) Em algum momento na carreira vocêfez ou deixou de fazer algo contra sua vontade? Como você lidou com isso Assim como a questão 3, essa também está relacionada ao Consentimento, pois remete a um sentimento de obediência de acordo com Silva (2009).

6) Chegando o momento para entrar na reserva você notou algum tipo de mudança em você? (Física, psicológica, comportamental, etc). Como você lida com isso?

7) Qual cenário você espera encontrar na transição para a reserva? Observando seus colegas que já passaram por isso, como você espera que seja a sua transição? Aconteceu como você imaginava?

8) Você procurou algum tipo de ajuda nesse momento de transição? A instituição procurou preparar você para a transição para a reserva? Por meio de programas de apoio, palestras, apoio psicológico, etc? Este apoio foi importante para você?

9) Após sua saída para a reserva você notou algum 
tipo de mudança em você? (Física, psicológica, comportamental, etc). Como você lida com isso? Essas 4 últimas questões tiveram como objetivo verificar como o militar lidou, de forma mais ampla, com a entrada para a reserva. A partir dessa questão esperava-se abrir espaço para uma narrativa sobre como ele regulou suas emoções nesse processo (GROSS, 2013), na tentativa de deixar essas perguntas abertas para que o sujeito pudesse respondê-la subjetivamente.

Como foi falado anteriormente, a população escolhida e foco desse estudo são os oficiais da polícia militar de Santa Catarina (PMSC) que estão próximos de passar pelo processo de entrada para a reserva remunerada e aqueles que já passaram, e a escolha dos oficiais ocorreu por exercerem cargos de gestão, o que supostamente eleva o status da função militar de comando, trazendo questionamentos sobre como seriam as reações ao deixar o cargo. A amostra foi por conveniência, na qual foram entrevistados presencialmente, em locais previamente acordados com o pesquisador, 14 oficiais da PMSC, todos do sexo masculino (no momento da pesquisa nenhuma mulher militar estava passando pelo processo de entrada para a reserva), todos com formação superior em Segurança Pública, com mais de 50 anos de idade e completando 30 anos de serviço. Cada entrevista durou em média de uma hora, e para esse artigo foram utilizados os recortes mais relevantes para o seu escopo, do ponto de vista dos autores. O número de entrevistados seguiu o "critério de saturação". Segundo Muchielli (1990), a saturação aparece na pesquisa qualitativa ao fim de certo tempo, quando os dados que são coletados deixam de serem novos, configurando-se uma estrutura comum sobre o fenômeno estudado.

O método de análise escolhido foi a Análise de Conteúdo, usando como referência o trabalho de Bardin (2016) que o caracteriza como sendo um conjunto de técnicas de análise das comunicações visando obter por procedimentos sistemáticos e objetivos de descrição do conteúdo das mensagens, indicadores (quantitativos ou não) que permitam a inferência de conhecimentos relativos às condições de produção destas mensagens. Esta técnica propõe analisar o que é explícito no texto para obtenção de indicadores que permitam fazer inferências. A partir da transcrição das entrevistas, fragmentos das narrativas foram categorizados e relacionados aos construtos. Com esta relação buscou-se caracterizar os geradores de cada vínculo e sua intensidade, bem como as estratégias de regulação emocional envolvidas no processo para a reserva remunerada.

\section{APRESENTAÇÃO E ANÁLISE DOS RESULTADOS}

A princípio foi analisado o construto Vínculo Organizacional e identificou-se que os fragmentos associados aos geradores do Comprometimento se manifestaram com mais força, se comparados aos vínculos de Consentimento e Entrincheiramento. Apesar disso, praticamente todos os indivíduos manifestaram em maior ou menor grau todos os geradores. Nota-se em especial no gerador "Forte crença, aceitação de valores e objetivos" um alinhamento com a perspectiva de Bastos (1994), que a fala dos entrevistados indica para um vínculo ativo, de dimensão afetiva, uma vez que Kanan (2008) já apontava para o fato de que os vínculos são originados das atitudes, emoções e sentimentos, da exploração de fatos e conceitos, dos pensamentos, crenças, expectativas, recordações, raciocínios, entre outros. Esse gerador alinha-se também à teoria de Meyer (2009), uma vez que os fragmentos dos relatos indicam forte relação com uma manifestação de desejo e de identificação, o que os caracterizam como exemplos de um comprometimento afetivo. Isso pode ser ilustrado pelo sentimento e desejo de fazer parte da PMSC expresso na narrativa: [...] fechava mais ou menos com os valores que eu julgava ter na época e daí pra frente foi uma sequência natural (Oficial 01). A fala também aponta para o alinhamento dos valores pessoais com os da Instituição, em sentido semelhante esses sentimentos também foram manifestados pelo Oficial 09: [...] quando entrei não era muito diferente do que eu vivia em casa, os valores eram os mesmos [...].

O segundo gerador relacionado ao Comprometimento é o "Forte desejo de manter o vínculo", na análise deste surgiram dissonâncias, poucas, mas que cabem uma breve investigação. $O$ forte desejo de fazer parte da instituição e uma grande identificação 
com o que ela representa, faz surgir no indivíduo, caso nem todas suas ambições se tornem realidade, um sentimento associado a frustrações e desapontamento. Entende-se que esses sentimentos possam ser observados em indivíduos de qualquer carreira, contudo, em uma organização militar podem ser potencializados pela característica intensa do vínculo e da natureza do trabalho. Muitas vezes, apesar do desejo de se afastar da carreira militar, muitos deles desistem da ideia e permanecem vinculados. O trecho a seguir marca essa característica quando o entrevistado foi questionado sobre a intenção de se afastar da carreira militar:

Em alguns momentos sim, atrelado a questão financeira e a questão de desgaste laborativo, em especial a trabalhar na folga dos outros, trabalhar a noite, virar a noite, trabalhar 24 horas, trabalhar final de semana, e etc (Oficial 02).

$\mathrm{Na}$ maioria dos relatos os indivíduos se mostraram satisfeitos com sua carreira, muito atribuído a um espírito de tenacidade forte e de persistência, sejam inatos ou moldados já nos primeiros anos de formação na academia da polícia militar. Este gerador do vínculo de comprometimento como avaliado por Rowe e Bastos (2008), é bom para o indivíduo e para a organização, gerando como resultado autoestima elevada e resultados positivos. Ainda nesse sentido os autores destacam a elevação dos sentimentos de pertencimento à organização e de segurança.

O terceiro gerador associado ao Comprometimento considerado neste estudo é o da "Intenção de esforço em favor da organização". Este por si só demonstra o quanto o oficial da polícia militar se dedica à instituição e se esforça para cumprir bem o seu papel, como nos aponta o Estatuto dos Policiais Militares de Santa Catarina nas exigências destinadas ao cumprimento da função relativas a valores e a ética que se espera do oficial: o sentimento de servir à comunidade, traduzido pela vontade inabalável de cumprir o dever policial-militar e pelo integral devotamento à manutenção da ordem pública mesmo com risco da própria vida; o civismo e o culto das tradições históricas; a fé na elevada missão da Polícia Militar; o espírito de corpo, orgulho do policial-militar pela organização onde serve; o amor à profissão policial- militar e o entusiasmo com que é exercida. E ainda o sentimento do dever e decoro da classe impõe a cada um dos integrantes da Polícia Militar, conduta moral e profissional irrepreensível, com a observância de diversos preceitos éticos. Essas características podem ser observadas na fala do Oficial 03 “... a gente veste a condição de policial em todos os momentos"

Em relação ao Entrincheiramento, Rodrigues e Bastos (2011) reconhecem três geradores: Investimento na Carreira, Limitação de Alternativas e o Custo Emocional. Fragmentos das entrevistas foram associados a esses, identificando assim a presença também desse tipo de vínculo. O primeiro gerador se situou nas narrativas dos oficiais em seu início, muito relacionado aos primeiros anos de suas formações, $o$ gasto psíquico e físico atribuído ao duro regime nos anos de academia se mostraram significativos na vivência desses indivíduos como policiais, somados ainda ao tempo dedicado e exigido para o cumprimento de suas funções, um verdadeiro investimento que ultrapassa os limites dos quarteis e adentra suas vidas privadas, interferindo muitas vezes na dinâmica familiar e de amizades. O fragmento a seguir contribui para este entendimento: A forma como nos dedicamos interfere sim nos relacionamentos [...], vivia o quartel [...], era focado nas exigências da carreira [...] os primeiros anos de formação são duros, lá na frente entendermos o porquê... (Oficial 07).

$\mathrm{O}$ segundo gerador traz um nítido significado associado a definição de entrincheirar-se. Quando não se vislumbram alternativas, ou seja, outras realidades que supririam as necessidades humanas, tende-se ao conformismo em relação aquela realidade que está posta, independente se esta satisfaz ou não os anseios do indivíduo. Como apontam Rodrigues e Bastos (2011), não é possível falar de uma permanência espontânea do trabalhador entrincheirado, mas sim em decorrência da sua necessidade. Dessa forma, associado ao que foi relatado pelos oficiais, o sentimento de identificação, aqui muito citado o termo "vocação", e suas formações especificas para a carreira militar, os restringiam ao ambiente das organizações militares, como manifesta o Oficial $06 . .$. acredito que essa seja a minha vocação, não me via fazendo outra coisa..."

Para Magalhães e Macambira (2013) o entrincheiramento é uma forma de vínculo desfavorável para o indivíduo, e também desfavorável para a organização, Rodrigues e Bastos (2011) nos passam a ideia 
de que estar entrincheirado é estar preso. Rodrigues e Bastos (2011) relacionam o conceito as dificuldades associadas à empregabilidade e a instabilidade do mercado de trabalho. Considerando os relatos dos oficiais esta perspectiva negativa associada ao entrincheiramento não encontrou respaldo, mesmo nos fragmentos que apontam para um descontentamento por parte do individuo, a percepção é que a carreira como oficial da polícia militar foi a decisão acertada.

O terceiro e último gerador do Entrincheiramento diz respeito aos custos emocionais associados à carreira de oficial militar, que tornariam difícil a saída da instituição. Estes custos foram muito associados ao desgaste frente a dinâmica da PMSC, desde a rotatividade de pessoal, que gera mudanças não só na vida do oficial, mas também de suas famílias, bem como as políticas e critérios para ascensão profissional, que demandam um envolvimento emocional e intelectual muito grandes. O Oficial 05 descreve tal vínculo quando fala que "... o dia a dia é intenso, muito diferente de outras atividades, quase sempre afetando a família."

O Consentimento está dividido em dois geradores: Obediência Cega e Aceitação Íntima. Na PMSC as bases hierarquia e disciplina ajudam a compreender melhor a forma como o Consentimento é experimentado pelos oficiais. O Estatuto dos Policiais Militares de Santa Catarina define estas bases e mostra a necessidade de aceitação por parte dos seus membros, sendo o respeito à hierarquia consubstanciado no espírito de acatamento à sequência de autoridade, e a disciplina pela observância e o acatamento integral das leis, regulamentos, normas e disposições que fundamentam o organismo policial-militar coordenando seu funcionamento regular e harmônico. E ainda que a disciplina e o respeito à hierarquia devem ser mantidos em todas as circunstâncias, entre policiais militares da ativa, da reserva e reformados.

Rodrigues e Bastos (2012) nos dizem que a natureza desse vínculo leva à ideia de que o indivíduo deverá ser um trabalhador que cumpre as normas da organização, segue o que está estabelecido, e, consequentemente, obedece aos superiores, revelando uma postura "passiva" frente à mesma. Apesar de terem que acatar ordens superiores, o termo passivo não se traduziu em algumas narrativas, essas demonstraram certo grau de liberdade para questionar determinadas ordens, não corroborando com uma postura passiva, como afirma Bastos et al. (2008). O trecho a seguir mostra isso: [...] poucas vezes foi me ordenado e me dito que a explicação viria depois, [...] sempre foi possível o diálogo (Oficial 08).

Dessa forma tanto o gerador Obediência Cega, relacionado ao acatamento à sequência de autoridade, quanto o gerador Aceitação Íntima, que diz respeito à internalização das normas e regulamentos, predizem um modelo cultural aceito e exigido neste tipo de organização para que a mesma possa funcionar de forma harmônica. Observou-se que, para os oficiais entrevistados, de forma inconsciente ou não, o trabalho assume uma característica protetiva muito importante. A atividade laborativa representa não apenas a prevenção contra a possibilidade de desenvolver vícios, mas constitui-se como símbolo de virtude, contribuindo para que esses sujeitos reforcem uma imagem de honradez e moralidade. Evidencia-se, desta forma, a importância do trabalho policial como fator de equilíbrio para esses indivíduos.

A posição destinada ao policial militar demanda dele uma devoção institucional e exige um direcionamento de suas capacidades físicas e mentais ao serviço. Esse indivíduo necessariamente deverá manter um vínculo muito forte com a instituição, o que trará fortes implicações para a construção de sua identidade profissional e para o trato de demandas emocionais.

A manutenção deste vínculo vai demandando ao longo da carreira cada vez mais investimentos físicos / psíquicos do policial militar na medida em que esse profissional, muitas vezes, abre mão da sua vida particular / familiar para dedicar-se ao trabalho.

Diante destas peculiaridades faz-se necessário estratégias de regulação das emoções, mesmo que em algumas vezes de forma inconsciente. Como nos diz Gross (2013), as funções da regulação emocional são a de defender o indivíduo de situações indesejáveis, evitar sofrimentos ou manter situações agradáveis, com o intuito de preservar o seu bem-estar.

A primeira estratégia e chamada de "Seleção da situação", relacionada aos aspectos antecedentes da regulação emocional, aponta para uma estratégia que se traduz, no caso dos oficiais entrevistados, num afastamento psíquico do evento reserva remunerada, como mostra a fala do Oficial 06 “... chegando próximo da reserva, procurei fazer mais atividades físicas." $\mathrm{O}$ 
foco se volta para as atividades rotineiras da polícia, uma troca que traz benefícios emocionais de curto prazo, mesmo porque o individuo terá que lidar com a situação mais a frente. Mesmo provisoriamente esta estratégia pode ser boa para o equilíbrio entre as necessidades e os desafios que a carreira ainda trará até a inatividade do Oficial.

A "Modificação da situação" é a segunda estratégia, ela diz respeito à intenção consciente em lidar com o problema, para que a realidade dos acontecimentos futuros possa ser mudada trazendo benefícios ao indivíduo. O fragmento a seguir retrata isso: "Fui me preparando uns anos antes, sabia que o dia ia chegar, uma hora iria me aposentar, muitos colegas não fazem isso, se desesperam quando chega a hora" (Oficial 07).

Outra estratégia é a "Atenção posicionada", muito usada quando a atenção é focada em eventos que podem ajudar a trazer emoções positivas e bom humor para uma situação pouco prazerosa (articulação entre distração e concentração). Neste ponto algumas narrativas se parecem, muitas demonstraram um sentimento de euforia em relação a vida pós reserva, como se o processo para a inatividade não existisse, pulando uma etapa, rumo a uma vida com tempo livre para projetos pessoais, mais tempo com família, viagens, etc, como aponta o Oficial 01 , “... a gente acaba experimentando uma sensação de liberdade, há uma euforia no sentido bom, agora vou ter todo tempo pra terminar meus projetos." O fato de demonstrarem certa indiferença pelo processo para a reserva, pode refletir tanto um desconhecimento associado a todos os problemas decorrentes da inatividade, quanto a um alto grau de satisfação e dever cumprido com relação a carreira.

A última estratégia relacionada aos aspectos antecedentes chama-se "Mudança cognitiva", segundo Gross (1998) é considerada a estratégia mais efetiva para atenuar o impacto emocional negativo. Um dos entrevistados, o Oficial 06, afirmou que “... esse sentimento de finitude é da natureza das coisas... faz parte...". Funciona como uma negação ao fato que existem problemas pós reserva, ou ver que existem boas oportunidades no depois, se comparar com outros indivíduos, ou ainda se conformar com a situação que está por vir. As narrativas traduziram este aspecto trazendo tanto respostas positivas ao fato de alguns oficiais verem o pós reserva como algo bom, assim como narrativas que mostram o conhecimento dos problemas e os aceitam conformando-se.

Os Aspectos Consequentes traduzem ações consideradas mais superficiais que as Antecedentes, que emergem depois que a emoção surgiu, ou ainda quando ela está em andamento. Diante do que foi apresentado pelos entrevistados com relação à primeira estratégia dos aspectos consequentes, "Mudar estados fisiológicos", está trazendo resultados positivos. A procura por atividades físicas e atividades que ocupem a mente, que mudem o estado de ansiedade, para um estado no qual os pensamentos e emoções se equilibrem, são benéficas para estes indivíduos, trazendo uma sensação de utilidade e bem-estar, que diminuem a ansiedade e um possível quadro depressivo. O trecho a seguir salienta isso: "Cabeça vazia oficina do diabo... sempre faço exercícios... diminui minha ansiedade... "(Oficial 12).

A segunda estratégia, "Regulação da expressão", diz respeito a dois extremos, quando o individuo suprime (tenta não mostrar) o que está sentindo ou quando ele intensifica (faz questão de mostrar) para modular a experiência emocional. A cultura policial e o meio militar exigem uma postura forte e rígida, na qual a fraqueza não é bem vista, como afirma o Oficial 10, "Nossa cultura faz com que pareçamos sempre fortes, e de certa forma é o que acontece..." Por esse motivo todas as narrativas trouxeram este mesmo entendimento, onde caso o indivíduo esteja passando por dificuldades, o mesmo suprime, finge que está tudo bem, para não ser mal visto pelos colegas. E depois da reserva essa atitude permanece, mesmo porque as bases da hierarquia e disciplina perpassam a ativa, sendo condutas também do policial da reserva.

A última estratégia relacionada aos aspectos consequentes, "Compartilhamento social" exprime um desejo em compartilhar as emoções na tentativa de atenuá-las ou modificá-las, conseguindo suporte e efetuando comparações que permitam a reavaliação de sentimentos. Segundo as narrativas dos oficiais, este compartilhamento acontece de forma natural, com a família, ou em encontros e eventos com colegas, mesmo que de forma acanhada, como dito nas estratégias anteriores, a fraqueza não é bem vista.

Para ilustrar como as análises foram desenvolvidas, categorizando os geradores a partir das falas dos entrevistados a seguir serão apresentados dois 
quadros. O Quadro 1 traz a síntese dos vínculos organizacionais, relacionando-os aos recortes das falas a partir dos geradores, que por sua vez foram definidos com base na bibliografia estudada.
Por sua vez, o Quadro 2 mostra as possíveis estratégias de regulação emocional e os fragmentos das falas dos entrevistados que se conectam com cada construto, considerando-se para realizar essa ligação os conceitos apresentados na literatura.

Quadro 1 Vínculos e Recortes das Falas dos Militares

\begin{tabular}{|c|c|c|}
\hline Vínculo & Gerador & Recortes das falas \\
\hline \multirow[t]{3}{*}{ Comprometimento } & Forte crença, aceitação de valores e objetivos & $\begin{array}{l}\text { "... fechava mais ou menos com os valores que eu julgava ter a } \\
\text { época e daí pra frente foi uma sequência natural..." }\end{array}$ \\
\hline & Forte desejo de manter o vínculo & $\begin{array}{l}\text { "Em alguns momentos sim, atrelado a questão financeira e a ques- } \\
\text { tão de desgaste laborativo, em especial a trabalhar na folga dos } \\
\text { outros, trabalhar a noite, virar a noite, trabalhar } 24 \text { horas, trabalhar } \\
\text { final de semana, e etc." }\end{array}$ \\
\hline & Intenção de esforço em favor da organização & "... a gente veste a condição de policial em todos os momentos" \\
\hline \multirow[t]{3}{*}{ Entrincheiramento } & Investimento na carreira & $\begin{array}{l}\text { "A forma como nos dedicamos interfere sim nos relacionamentos } \\
\text { [...], vivia o quartel [...], era focado nas exigências da carreira[...]os } \\
\text { primeiros anos de formação são duros, lá na frente entendermos o } \\
\text { porquê.... }\end{array}$ \\
\hline & Limitação de Alternativas & $\begin{array}{l}\text { ". acredito que essa seja a minha vocação, não me via fazendo outra } \\
\text { coisa..." }\end{array}$ \\
\hline & Custo Emocional & $\begin{array}{l}\text { "... o dia a dia é intenso, muito diferente de outras atividades, quase } \\
\text { sempre afetando a família." }\end{array}$ \\
\hline \multirow[t]{2}{*}{ Consentimento } & Obediência Cega & $\begin{array}{l}\text { "...poucas vezes foi me ordenado e me dito que a explicação viria } \\
\text { depois,..." }\end{array}$ \\
\hline & Aceitação Íntima & "...sempre foi possível o diálogo." \\
\hline
\end{tabular}

Fonte: Autoria Própria, 2020

Quadro 2 Estratégias de Regulação Emocional e Recortes das Falas dos Militares

\begin{tabular}{l|l}
\hline \multicolumn{2}{c}{ Aspectos Antecedentes } \\
\hline Estratégias de Regulação Emocional & Recortes das Falas \\
\hline Seleção da Situação & "... chegando próximo da reserva, procurei fazer mais atividades físicas." \\
\hline Modificação da Situação & $\begin{array}{l}\text { "Fui me preparando uns anos antes, sabia que o dia ia chegar, uma hora iria me aposentar, muitos } \\
\text { colegas não fazem isso, se desesperam quando chega a hora". }\end{array}$ \\
\hline Atenção Posicionada & $\begin{array}{l}\text { "... a gente acaba experimentando uma sensação de liberdade, há uma euforia no sentido bom, } \\
\text { agora vou ter todo tempo pra terminar meus projetos." }\end{array}$ \\
\hline Mudança Cognitiva & "... esse sentimento de finitude é da natureza das coisas... faz parte...." \\
\hline Mudanças de Estados Fisiológicos & Aspectos Consequentes \\
\hline Regulação da Expressão & "Cabeça vazia oficina do diabo... sempre faço exercícios... diminui minha ansiedade..." \\
\hline Compartilhamento Social & "... tenho contato com outros coletas, sempre lembramos do tempo da ativa". \\
\hline
\end{tabular}

Fonte: Autoria Própria, 2020 


\section{CONSIDERAÇÕES FINAIS}

A pesquisa cujos resultados foram aqui relatados teve como objetivo compreender as mudanças do vínculo entre o policial e Polícia Militar, bem como as estratégias de regulação emocional adotadas por esses sujeitos, considerando o contexto em que precisam passar pelo processo para a reserva remunerada, que é o equivalente à aposentadoria no universo civil.

Foi evidenciado no presente estudo que a importância e o significado do trabalho policial para os oficiais entrevistados contribuíram fortemente para a construção de suas identidades, em especial, pelo nível de desempenho e responsabilidade a que são expostos os policiais militares hierarquicamente superiores, reforçando assim a ideia do papel estruturante que o trabalho cumpre na vida do indivíduo (SANTOS, 1990).

Verificou-se a partir da análise de conteúdo, feita sobre as transcrições das entrevistas, diversos elementos determinantes na construção do vínculo organizacional. Conforme observado, o Comprometimento, o Entrincheiramento e o Consentimento foram manifestados pelos Oficiais, em menor ou maior grau, o que demonstra a presença desses elementos na forma como se conectam e se identificam com a PMSC.

Com as especificações dos diversos geradores desses tipos de Vínculos e as suas ligações às narrativas dos oficiais, foi demonstrado que há forte relação do Comprometimento com o trabalho policial. O alto envolvimento com as atividades da função, a disposição em prol da organização, a postura ética e os valores morais similares, o sentimento de lealdade, a aceitação das normas e procedimentos, são alguns traços encontrados nas narrativas, que denotam um alto grau de Comprometimento, assim como outras características de cunho instrumental, que se relacionam com o "estar satisfeito", uma baixa intenção em abandonar a carreira, atribuídas aqui ao conceito de Entrincheiramento. O Consentimento, por sua vez, se manifestou na própria essência da carreira militar, estruturada em um sistema de forte respeito à hierarquia e à disciplina.

As narrativas dos indivíduos desse estudo evidenciam que para esses profissionais, quanto mais forte for o vínculo, mais difícil é a passagem para a inatividade relacionada a reserva remunerada, ou seja, o "pensar a reserva". Como se vê, para alguns indivíduos a reserva remunerada é expressa como algo inimaginável, distante de suas realidades ao ponto de se expressar na terceira pessoa, como se fosse outro profissional que estivesse próximo de se afastar da atividade. A reserva se mostra para esses indivíduos como um cenário marcado pelo vazio, pela insegurança e que, por isso, tem que ser devidamente preenchido com atividades e projetos paralelos.

A mudança do vínculo organizacional, segundo as percepções dos oficiais, começa a acontecer justamente por esse "pensar a reserva". A partir do momento que existe uma sintonia entre o que foi conquistado dentro da carreira como policial militar, o cumprimento da sua missão institucional e os planos bem definidos para o futuro, o afastamento se torna algo recompensador, no entanto, quando estas características não estão alinhadas o que se nota é um intenso sentimento de perda. Neste sentido, a mudança pode resultar em intenso sofrimento ao indivíduo, tornando essa etapa de sua vida algo que lhe traga profunda preocupação ou até mesmo algo de menor significado.

São em situações como essa, nas quais o indivíduo não consegue visualizar de uma forma positiva o momento em que encontra, no caso a sua eminente inatividade, que os mecanismos de regulação emocional precisam ser estimulados, configurando, consciente ou inconscientemente, atitudes e comportamentos geradores de emoções, que se não forem bem elaborados internamente, podem desencadear desiquilíbrios e, consequentemente, eventuais problemas para o convívio organizacional e também familiar.

O estudo desenvolvido permitiu verificar que existem fortes indícios de que, de fato, o processo de passagem para a reserva remunerada é um período difícil para muitos Oficiais e que apresenta efeitos emocionais que não podem ser ignorados. Nisso, a organização assume um importante papel, uma vez que pode contribuir por meio de práticas e ações institucionais que auxiliem nesse momento que é inevitável, contribuindo para o estímulo e fortalecimento dos processos de regulação emocional dos indivíduos.

A partir dos conceitos trazidos pelas bases teóricas e as narrativas dos Oficiais, conclui-se que a 
mudança do vínculo organizacional no processo para a reserva não é algo trivial, pois como visto apresenta reflexos nas relações do indivíduo em todos os seus meios sociais, em especial na organização. Importante destacar ainda, que esse evento não está delimitado no tempo, uma vez que alguns indivíduos podem começar a vivenciá-lo muito antes da sua chegada, enquanto outros só o percebem depois de terem deixado a instituição. A mudança acontece para cada um no compasso de suas capacidades de internalização das características da organização, ou seja, quanto maior o vínculo de Comprometimento, mais emoções estarão atreladas a este afastamento.

Por fim, foi observado também que o Entrincheiramento e o Consentimento, tendem a se esgotarem com a proximidade da reserva, e após a efetiva saída do policial, que apesar de ainda estar sob princípios e normas militares, já não as sentem com a mesma intensidade. Portanto, o "pensar a reserva" da início ao processo, e a sintonia em que oficial se encontra com a organização dita a sua intensidade, dentro ou fora dela.

Ressalta-se que esta pesquisa foi um passo no entendimento do papel da regulação emocional na atividade policial, especificamente neste caso analisando sua relação com a passagem para a reserva remunerada em Oficiais da PMSC. Contudo, existem diversas abordagens possíveis para o tema que não foram aqui contempladas como por exemplo analisar o tema em outros níveis hierárquicos, buscar compreender o processo de passagem para a reserva em outras instituições militares ou mesmo em outros órgãos da segurança pública, que assumem uma importante função social. Ou seja, essa pesquisa não pretende encerrar a discussão sobre os assuntos aqui abordados e sim gerar ideias para pesquisas futuras.

\section{REFERÊNCIAS}

ALVARES, K.P.; GRILlO RODRIGUES, A. P. Vínculos Organizacionais: uma análise em relação ao desempenho. Revista Gestão \& Planejamento. v.21, p.156-171, dez/jan 2020.

BARDIN, L. Análise de Conteúdo. Edições 70. Lisboa, 2016
BASTOS, A. V. B. Comprometimento no Trabalho: A estrutura dos vínculos do trabalhador com a organização, a carreira e o sindicato. 1994. 293 f. Tese (Doutorado em Psicologia) - Instituto de Psicologia, Universidade de Brasília-UnB. Brasília, 1994.

CABEZA, M. C. Más Allá Deltrabajo: El ócio de los jubilados. Revista Mal-estar e subjetividade, v. 9, p 13-42. Fortaleza, 2009.

GODOI, C. K.; BALSINI, C. P. V. A pesquisa qualitativa nos estudos organizacionais brasileiros: uma análise bibliométrica. In: SILVA, A. B.; GODOI, C. K.; BANDEIRA-DEMELO,R. (orgs). Pesquisa qualitativa em estudos organizacionais: paradigmas, estratégias e métodos. 2. ed. São Paulo, 2010, p. 89-113.

GONDIM, S. M. G.; RIBEIRO W. R. B.; PEREIRA, C. R. Personalidade e bem-estar subjetivo de trabalhadores: moderação da regulação emocional. Rio de Janeiro: Arquivos brasileiros de psicologia, 2017.

GONDIM, S.M.G.; BORGES, L.O. Significados e sentidos do trabalho do home-office: desafios para a regulação emocional. Disponível em: https://www. sbpot.org.br/ central-de-conteudo-covid19/wp-content/uploads/2020/04/SBPOT_TEMATICA_5_Gondim_Borges.pdf. Acesso em: dezembro de 2020.

GRILLO RODRIGUES, A. P. Os vínculos com a organização e a regulação emocional de servidores públicos. Tese Doutorado - Universidade Federal da Bahia. Salvador: Escola de Administração, 2012. Disponível em: http://www.adm.ufba.br/pt-br/publicacao/os-vinculos-com-organizacao-regulacao-emocional-servidores-publicos

GROSS, J. J. Handbook of emotion regulation. London: The Guilford Press. 2013.

Emotion regulation. Past, present, future. Cognition and Emotion, 13, 551-573. 1999.

The emergent field of emotion regulation: Na integrative review. Review of General Psychology, 2, 271-299. 1998. 
KANAN, L. A. Características do processo de vinculação de coordenadores de curso com o trabalho e com a universidade. Tese. Universidade Federal de Santa Catarina. Florianópolis, 2008. Disponível em: http://bit.ly/2P86Rqd

KEGLER, P.; MACEDO, M. M. K. Trabalho e aposentadoria militar: singularidades de uma travessia psíquica. Psico-USF, Bragança Paulista, v. 20, n. 1, p. 25-38, jan./abr. 2015. Disponível em: http://bit. ly/2G8VrP9

KRAMER, G. G. Vínculos Organizacionais: um estudo de caso em uma organização pública. Dissertação. Curitiba: UFPR, 2003. Disponível em: https://acervodigital.ufpr.br/handle/1884/32556

LOPES, M. Aposentadoria: PPA-Programa de Preparação para Aposentadoria cultive esta semente! V Mostra de produções cientificas. Goiânia: Universidade Católica de Goiás, 2010.

MAGALHÃES, M. O.; MACAMBIRA, M. O. Estilos Interpessoais e Vínculos com a Organização: Diferenças de Gênero. Psico, PUCRS, v. 44, n. 1, jan./mar. Porto Alegre: 2013. Disponível em: http:// bit.ly/2DaQe8P

MENDES, A. M. Escuta e ressignificação do sofrimento: ouso de entrevista e análise categorial nas pesquisas em clínica do trabalho. In Sociedade Brasileira de Psicologia Organizacional e do Trabalho (Org.), Anais Eletrônicos do II Congresso de Psicologia Organizacional e do Trabalho. Brasília: 2006.

MEYER, J.P. Commitment in Organizations: Accumulated Wisdom and New Directions. Florence, KY: Routledge/Taylor and Francis Group, 2009.

MEYER, J. P., \& ALLEN, N. J.A three-component conceptualization of organizational commitment. Human Resource Management Review, 61-89. 1991.

MUCHIELLI, A. Les Méthodes Qualitatives. Coleção Que sais-je?. Presses Universitaires de France. Paris, França. 1990.
PICHON-RIVIÈRE, E. Teoria do vínculo. Martins Fontes. São Paulo: 2000.

PINHO, A. P.; BASTOS, A.V.B.; ROWE, D.E.O. Diferentes Vínculos Indivíduo-Organização: explorando seus significados entre gestores. RAC, Rio de Janeiro, v. 19, 3a Edição Especial, art. 3, pp. 288-304, 2015.

RODRIGUES, A.C.A.; BASTOS, A. V. B. Entrincheiramento organizacional: construção e validação da escala. Psicologia: Reflexão e Crítica, v. 25 , n. 4 , pp. 688-700, 2012.

RODRIGUES, A. C. A.; BASTOS, A. V. B. Entrincheiramento organizacional: proposta de um novo vínculo indivíduo-organização. São Paulo: Casa do Psicólogo. 2011.

ROWE, D. E. O.; BASTOS, A. V. B. Comprometimento ou entrincheiramento na carreira? Um estudo entre docentes do ensino superior. Anais do Encontro Nacional da Associação Nacional de Pós-Graduação e Pesquisa em Administração. Rio de Janeiro, 2008.

SANTOS, M. de F. Identidade e Aposentadoria. EPU. São Paulo, 1990SILVA, E. E. da C. Consentimento Organizacional: uma proposta de medida para o construto. Dissertação de mestrado.Universidade Federal da Bahia. Instituto de Psicologia. 2009.

SILVA, E. C.; BASTOS, A. V. B. A escala de consentimento organizacional: construção e evidência de validade. Revista Psicologia, Organizações e Trabalho, 10,7-22. 2010. Disponível em: https://periodicos.ufsc. br/index.php/rpot/article/view/17273/15835

STAKE, R. Pesquisa Qualitativa: estudando como as coisas funcionam. Porto Alegre: Penso, 2011.

TSUTSUI, M. Qualidade de vida e preparação do Policial Militar para reserva remunerada. Artigo (Especialização em Formulação e Gestão de Políticas Públicas). Universidade Estadual de Maringá. 2009. 
UNGARI, D. F. A influência da cultura organizacional no desenvolvimento dos vínculos organizacionais: estudo de caso na polícia militar de Santa Catarina. 147 p. Dissertação (Mestrado) - Universidade do Estado de Santa Catarina, Centro de Ciências da Administração e Socioecônomicas, Mestrado em Administração, Florianópolis, 2019.

UNGARI, D.F.; GRILlO RODRIGUES, A. P. A Influência da Cultura Organizacional no Desenvolvimento dos Vínculos do Indivíduo com a Organização. Revista Eletrônica de Estratégia \& Negócios, v. 13, n 2, p. 167-195, 2020.

ZANELLI, J. C.; SILVA, N. Programa de preparação para aposentadoria. Insular. Florianópolis, 1996. 